\title{
PERANCANGAN DAN PENGUJIAN ALAT UNTUK MONITORING KELEMBABAN TANAH DAN PEMBERIAN PUPUK CAIR PADA TANAMAN CABAI BERBASIS INTERNET Of THINGS
}

\author{
${ }^{1}$ Arafat \\ ${ }^{2}$ Silvia Ratna \\ ${ }^{3}$ Wagino \\ ${ }^{4}$ Ibrahim \\ ${ }^{1}$ Teknik Informatika, Teknologi Informasi \\ ${ }^{2}$ Sistem Informasi, Teknologi Informasi \\ aaruniska@gmail.com \\ terrasin06@gmail.com
}

\begin{abstract}
ABSTRAK
Tanah sebagai faktor utama dalam pertanian harus dipertimbangkan sebaik mungkin agar dapat memberikan hasil seperti yang diharapkan. Salah satunya dengan memanfaatkan teknologi komputer dan internet untuk memonitor kelembaban tanah. Kelembaban tanah adalah salah satu faktor lingkungan yang mempengaruhi pertumbuhan tanaman. Salah satu inovasi teknologi informasi dan komunikasi di bidang pertanian adalah penggunaan Internet of Things. Dengan menggunakan Internet Of Things, hal itu bisa dilakukan untuk memantau kelembaban tanah yang menjadi media tanam tanaman hortikultura. mengetahui nilai kelembaban tanah akan sangat berguna untuk dapat menentukan langkah atau penanganan tanah. Masalah utama adalah menurun nya tingkat kesuburan tanah yang berpengaruh terhadap menurun nya produktifitas hasil panen cabe. Dengan alat yang dibuat nantinya, tingkat kesuburan tanah akan terjaga.
\end{abstract}

Kata kunci: ESP32,Greenhouse, Soil Moiusture, Internet of Things 


\section{PENDAHULUAN}

Perkembangan teknologi informasi dan komunikasi sekarang ini sudah banyak digunakan pada berbagai bidang tak terkecuali pada bidang pertanian. Indonesia adalah sebagai negara agraris dengan sumber daya alam yang besar harus diolah secara maksimal. Tanah sebagai faktor utama dalam holtikultura harus diperhatikan dengan sebaik-baiknya agar dapat memberikan hasil sesuai dengan yang diharapkan. Salah satunya dengan cara memanfaatkan teknologi komputer dan internet untuk memonitor kelembaban tanah.

Tanah merupakan media tumbuh yang ideal bagi tanaman, sehingga tanaman akan tumbuh subur dan memiliki produktivitas yang baik jika ditanam di tanah. Faktor kelembaban sangat penting bagi tanah untuk proses pelapukan mineral dan bahan organik tanah, selain itu juga sebagai media gerak unsur hara ke akar-akar tanaman. Akan tetapi jika terlalu lembab maka pergerakan udara didalam tanah akan terbatasi, menghalangi akar tanaman mendapatkan oksigen sehingga menyebabkan kematian. Untuk mengetahui informasi kelembaban tanah adalah dengan mengukur langsung, akan tetapi metode ini membutuhkan waktu dan tenaga yang besar.Untuk memudahkan dalam pemantauan

fluktuasi dalam waktu yang cepat, dibuatlah alat ukur kelembaban tanah berbasis mikrokontroller.

Inovasi teknologi informasi dan komunikasi dalam bidang pertanian adalah penggunaan sensor dan Mikrokontroller. Dengan menggunakan peralatan teknologi informasi dan komunikasi maka dapat dilakukan monitoring terhadap kelembaban tanah yang menjadi media tanam dari tanaman Pertanian. mengetahui nilai kelembaban tanah akan sangat bermanfaat untuk bisa menentukan langkah atau penanganan terhadap tanah tersebut. Jika kelembaban tanah kurang dari ambang batas yang dibutuhkan oleh tanaman holtikultura tersebut maka secara otomatis akan dilakukan penyiraman. Selain itu pada proposal penelitian ini juga akan memberikan pupuk cair pada tanaman untuk menjaga kesuburan tanaman. Dengan adanya sistem pemupukan secara otomastis diharapkan akan meningkat kan produktifitas hasil panen tanamaman cabai, sehingga hasil panen bisa terus berlanjut. Pemberian pupuk cair di lakukan setiap satu minggu sekali secara terjadwal.

Berdasarkan latar belakang yang telah dikemukakan, maka penelitian yang dilakukan mengenai "Perancangan dan Pengujian Alat Untuk Monitoring Kelembaban Tanah Dan Pemberian Pupuk Cair Pada Tanaman Cabai Berbasis Internet Of Things"

Hasil penelitian ini diharapkan menjadi solusi untuk

meningkatkan kualitas dan kuantitas produksi sayuran di Indonesia baik

pada musim kemarau maupun musim hujan sehingga harga sayur mencapai kestabilan di tiap tahunnya.

\section{METODE PENELITIAN}

Penelitian ini dilakukan berdasarkan tahapantahapan penting yang dikerjakan dengan berorientasikan kepada indikator keberhasilan dalam menghubungkan ESP32 dengan sensor yang digunakan sehingga dapat digunakan untuk menyelesaikan permasalahan multi objektif. Untuk dapat mencapai, indikator tersebut, maka tahapan-tahapan penelitian ini adalah sebagai berikut :

1. Analisa masalah, dalam hal ini kebutuhan menganalisa permasalahan yang akan diteliti mengenai greenhouse.

2. Analisa kebutuhan, dalam hal ini segala kebutuhan dalam meneliti baik dari jurnal, buku, literatur-literatur, alat dan bahan.

3. Mendesain alat yang akan dibangun dengan menggunakan ESP32 beserta sensor DHT11 dan Capasitive Soil Moisture.

4. Membuat program dengan menggunakan arduino IDE

5. Menguji alat dengan kode program yang dibuat.

6. Menguji alat yang dibuat dengan koneksi internet.

\section{Perancangan Sistem}

Desain dan implementasi alat pengukur monitoring greenhouse memiliki langkah-langkah sebagai berikut :

1. Pengendali yang digunakan adalah Modul IoT ESP32

2. DHT 11 yang digunakan untuk membaca nilai suhu dan kelembaban

3. Capasitive Soil Moisture yang digunakan untuk membaca nilai kelembaban pada tanah

4. Oled LCD yang digunakan untuk menampilkan nilai kelembaban pada green house

5. Software yang digunakan adalah Arduino IDE untuk pemrograman modul ESP32

6. Blynk sebagai server Internet of Things 


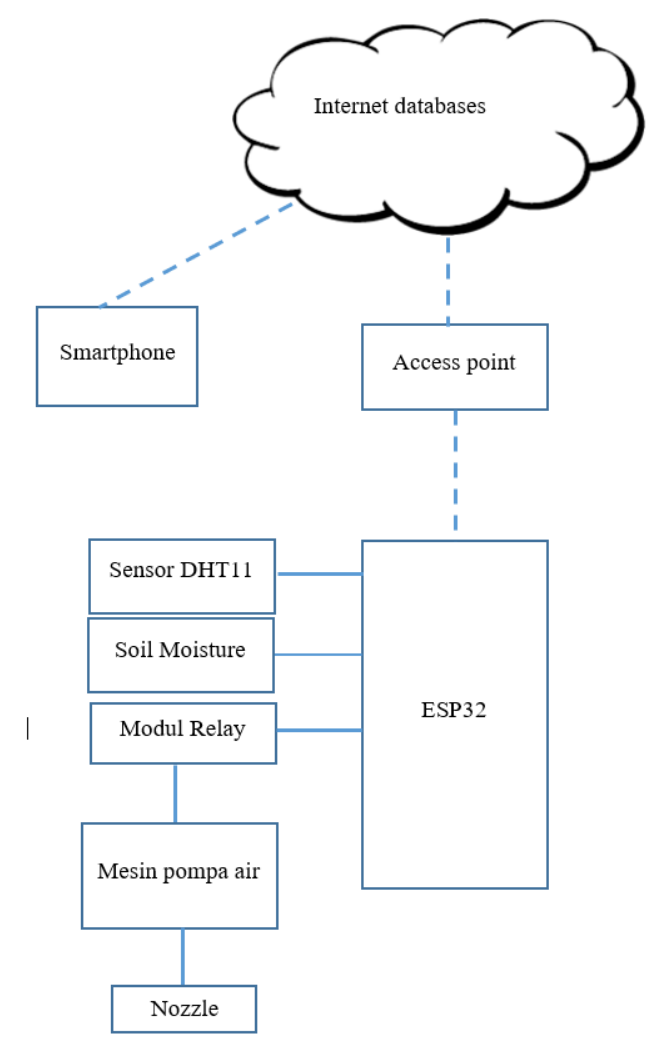

Gambar 1 Cara kerja alat

Cara Kerja:

1. Sensor Capasitive Soil Moisture digunakan untuk membaca kadar air yang terkandung pada media tanah. Caranya dengan menancapkan sensor capasitive soil moisture ke dalam tanah

2. OLED 128x64 pixels digunakan untuk menampilkan nilai kelembaban dan kadar air pada layar.

3. Blynk digunakan untuk memberikan informasi kelembaban dan kadar air pada tanah serta mengatur nilai ambang kelembaban ruangan dan kelembaban tanah yang di tampilkan pada smartphone android.

\section{HASIL DAN PEMBAHASAN}

\section{Flowchart}

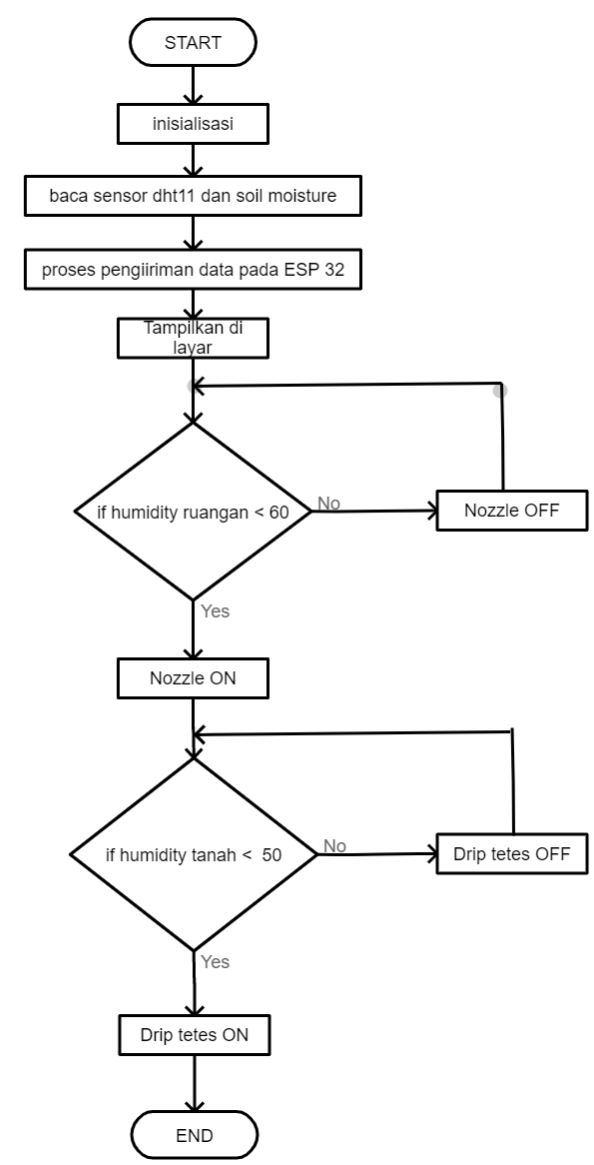

Gambar 2 Alur proses alat greenhouse

Pembacaan Program Sofware akan berlangsung Otomatis ketika Tombol Start ditekan kemudian Inisialisasi Aktuator berjalan dan pembacaan Sensor Capasitive Soil Moistur dan Sensor DHT11 berlangsung dengan tombol Stat di tekan. Pada pembacaan Sensor tersebut akan di Proses dan di Inisialisasi pada ESP32. Dalam proses tersebut data yang dapat di baca Sensor di kirimvmenggunakan Modul ESP 32 .Dalam proses tersebut ESP32 akan mengontrol jika Sensor DHT11 membaca kelembaban ruangan greenhose dengan nilai $<60$ $\%$, makan nozzel akan menyala dengan otomatis. Jika nilai kelembaban ruangan $<=85 \%$ maka nozzle akan Off. Pembacaan sensor capasitive soil moistur yang mampu membaca tingkat kelembaban tanah dalam kondisi kering, jika kelembaban tanah $<50 \%$, maka pompa air akan menyala mengalirkan air melalui drip tetes ke polybag sampai nilai kelembaban tanah mencapai $80 \%$. Selanjutnya pompa akan mati jika sudah mencapai nilai tersebut.

\section{Perancangan Perangkat Keras}

Pada gambar 4.2 merupakan perancangan alat sistem monitoring suhu dan kelembaban greenhouse dimana terdapat sensor DHT11 dan soil moisture. 


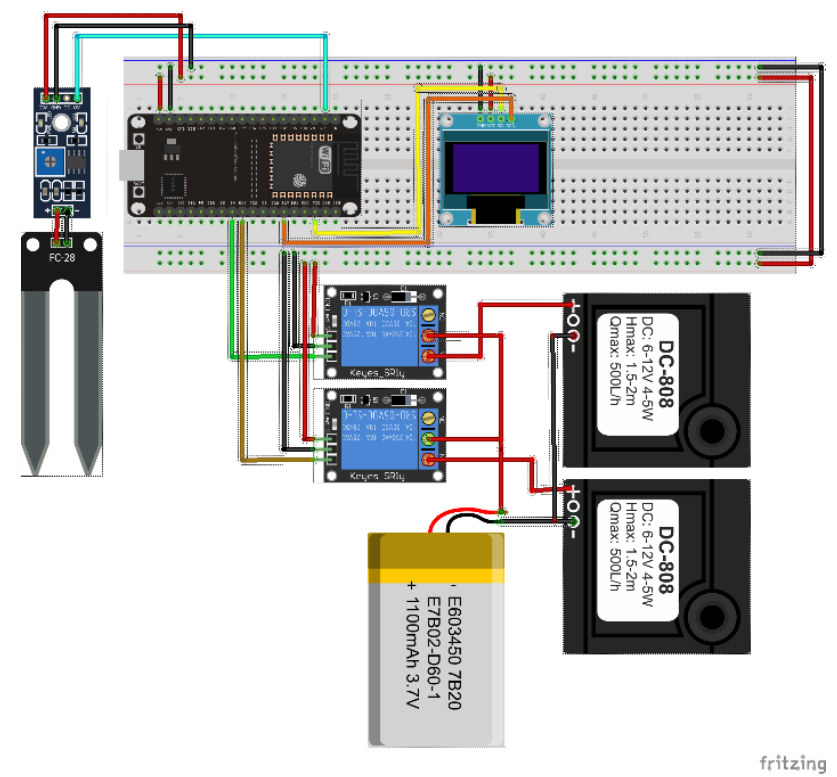

Gambar 3 Rancangan alat monitoring suhu dan kelembaban greenhouse

\section{Hasil Rancangan Perangkat Keras}

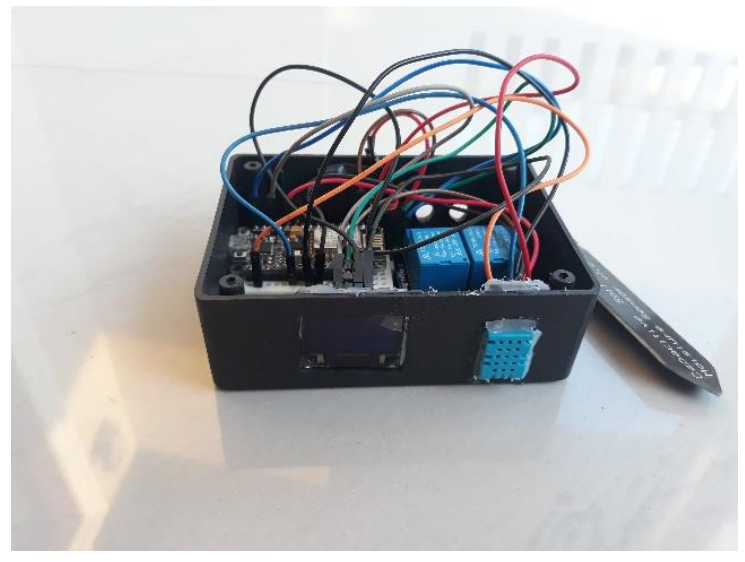

Gambar 4 Hasil rancangan perangkat keras monitoring untuk pengendali suhu dan kelembaban greenhouse

\section{Pengujian Koneksi}

Tujuan pengujian ini adalah untuk memastikan bahwa Modul ESP32 bekerja dengan baik. Pengujian yang pertama dilakukan adalah memeriksa apakah modul esp32 dapat terkoneksi ke jaringan Wi-Fi / Access point yang menyediakan akses internet. Pengujian dilakukan dengan menyalakan alat dan menunggu sampai terhubung dengan Access Point atau jaringan Wi-Fi yang telah disetting sebelumnya.

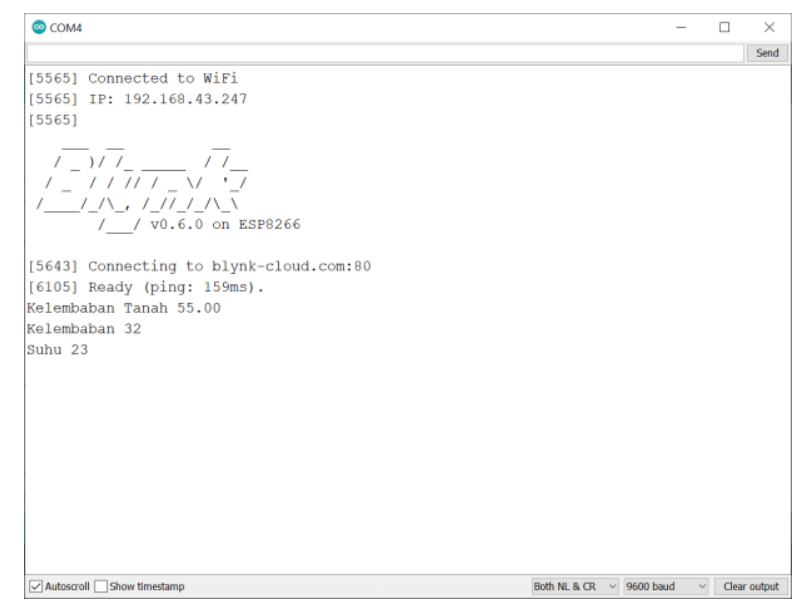

Gambar 5 Pengujian koneksi esp32 ke internet melalui serial monitor

\section{Pengujian Alat Pada Tanaman Cabe}

Untuk menjaga suhu dan kelembaban pada ruangan greenhouse di pasang sensor DHT11 dan nozzle untuk memberikan pengkabutan. Nozzle akan bekerja jika kelembaban pada ruangan greenhouse mencapai $60 \%$, secara otomatis berhenti melakukan pengkabutan jika kelembaban ruangan greenhouse mencapai 85 $\%$.

\section{Pengujian Internet of Things}

Pada gambar 4.5 merupakah hasil pembacaan sensor melalui aplikasi blynk yang terhubung dengan internet dan hasilnya juga bisa dilihat melalui layar LCD. Dimana hasil yang ditampilkan melalui aplikasi blynk dan layar LCD tidak ada perbedan angka yang dihasilkan. Pada aplikasi blynk terdapat slider untuk mengatur parameter nila suhu dan kelembaban ruangan serta kelembaban tanah untuk mengatur alat supaya dapat bekerja secara otomtis dan tombol simpan untuk menyimpan perubuhan yang telah dilakukan.

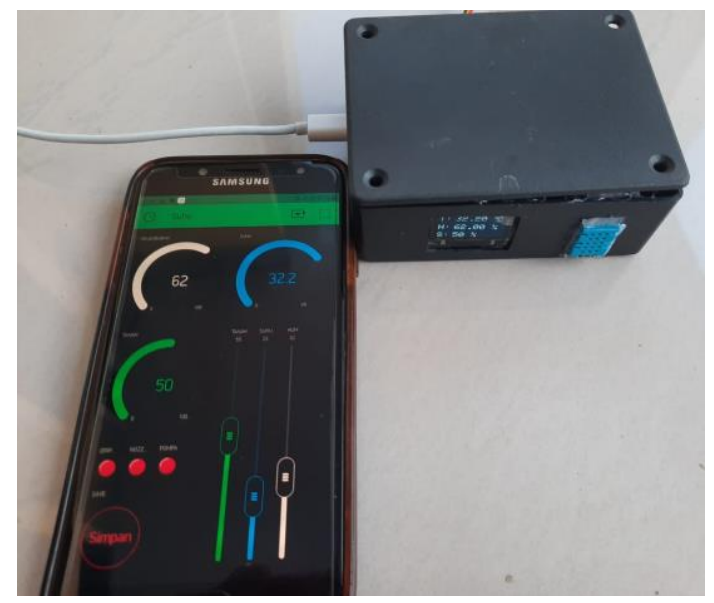

Gambar 8 tampilan kondisi suhu dan kelembaban melalui aplkiasi blynk dan layar LCD 


\section{Sistem Otomatis Sensor}

Tujuan pengujian ini adalah untuk memastikan sistem otomatis yang telah dibuat dapat bekerja dengan baik dan tepat. Pengujian dilakukan dengan mengamati kapan sistem otomatis bekerja.

Tabel 2 hasil pengujian pompa

Nilai Kelembaban Kondisi Pompa
Tanah

\begin{tabular}{cc}
\hline $\mathbf{5 0} \%$ & Nyala \\
\hline $\mathbf{6 0} \%$ & Nyala \\
\hline $\mathbf{7 0} \%$ & Mati \\
\hline $\mathbf{8 0} \%$ & Mati \\
\hline $\mathbf{9 0} \%$ & Mati \\
\hline
\end{tabular}

\section{Analisis Hasil Pengujian}

Setelah seluruh komponen terintegrasi secara menyeluruh satu sama lain dan terkoneksi terhadap server. Kemudian dilakukan pengujian secara keseluruhan apakah sistem dapat bekerja dengan baik dan telah tersingkronisasi satu dengan yang lainnya. Dari pengujian keseluruhan ini didapatkan hasil bahwa pompa 1 yang digunakan sebagai kontroler dapat bekerja dengan baik dan dapat beroprasi secara otomatis dengan cara membaca nilai suhu dan kelembaban udara pada parameter yang sudah ditetapkan, bila mana nilai suhu dan kelembaban udara melebihi nilai yang telah ditetapkan, pompa 1 akan bekerja untuk memberikan pengkabutan dengan nozzel sehingga dapat membuat suhu dan kelembaban udara di dalam greenhouse menjadi lebih stabil. Pompa 1 air dapat bekerja dengan baik sehingga dapat mengatur suhu dan kelembaban pada greenhouse. Sedangkan pompa 2 juga dapat bekerja dengan baik dan bekerja secara otomatis. Pompa 2 digunakan untuk meyirami tanaman yang berada didalam polybag dengan menggunakan drip tetes pada masingmasing polybag. Pompa air akan otomatis bekerja jika kelembaban tanah memiliki tingkat kelembaban $50 \%$ dan berhenti bekerja jika kondisi kelembaban tanah mencapai $80 \%$.

\section{KESIMPULAN}

1. Perancangan Sistem Alat Monitoring Untuk Pengendali Suhu dan Kelembaban Greenhouse Berbasis Internet Of Things dirancang menggunakan capasitive soil moisture sensor untuk mendeteksi kelembaban tanah dan sensor DHT-11 yang berfungsi untuk membaca nilai dari kelembaban udara dan juga suhu di dalam greenhouse. ESP32 berfungsi sebagai pemroses program dari perangkat sensor berbasis wifi. ESP32 sebagai platform IoT yang berfungsi untuk mengirim data yang dibaca oleh sensor untuk ditampilkan pada blynk kondisi greenhouse secara real time. pengiriman data yang dilakukan oleh modul wifi ESP32 menggunakan protokol MQTT.

2. Perancangan Sistem Alat Monitoring Untuk Pengendali Suhu dan Kelembaban Greenhouse Berbasis Internet Of Things dalam pelaksanaanya yaitu menggunakan tanaman yang ditanam pada polybag sebagai media untuk mengukur nilai dari kelembaban tanah. Tanah yang digunakan dengan kondisi kering, basah dan juga agak basah untuk menguji nilai dari pembacaan oleh sensor capasitive soil moisture. Untuk pengujian sensor DHT-11 yaitu dengan cara sensor diletakkan pada ruangan greenhouse, kondisi suhu dan kelembaban ruangan dapat di lihat pada layar oled LCD dan aplikais blynk.

3. Untuk mengatur nilai ambang batas suhu dan kelembaban dapat dilakukan pada aplikasi blynk dengan cara menggeser sesuai dengan paramaeter yang di inginkan untuk mengatur alat otomatis bekerja mengatur suhu dan kelembaban greenhouse serta kelembaban tanah pada polybag.

\section{DAFTAR PUSTAKA}

Hidayat, T. (2017). Internet of Things Smart Agriculture on ZigBee: A Systematic Review. InComTech: Jurnal telekomunikasi Dan Komputer, 8(1), 7586.

https://doi.org/10.22441/incomtech.v8i1.2 146

Imam, A., \& Gaur, D. (2018). Smart Greenhouse Monitoring using Internet of Things. International Journal of Advanced Research in Electronics and Communication Engineering (IJARECE), 7(5), 519-523. Retrieved from http://ijarece.org/wpcontent/uploads/2018/05/IJARECE-VOL7-ISSUE-5-519-523.pdf

Iot, I., \& Remote, P. (2018). Rangkaian Kontroller. 1(1), 56-60. 
Mulyana, A., \& Sofyan, S. (2015). Alat Ukur Parameter Tanah dan Lingkungan Berbasis Smartphone Android, 2(2), 165-178.

Mehta, M. (2015). Esp 8266 : a Breakthrough in Wireless Sensor Networks and, 6(8), 7-11.

PhD, S. M. (2014). Build Internet of Things Projects With the Arduino Platform.

Rovai Marcelo Jose, P. M. T. (2016). MJRoBot Tutorials ArduFarmBot (Vol. 1).

Saputro, I. A., Suseno, J. E., Widodo, E., Fisika, D., Sains, F., \& Diponegoro, U. (2017). Rancang bangun sistem pengaturan kelembaban tanah secara real time menggunakan mikrokontroler dan diakses di web, 6(1), 40-47.

Octavianes, F., Gunawan, A., \& Styorini, W. (n.d.). Pengukur Kelembaban Tanah dan Suhu Udara sebagai Pendeteksi Dini Kebakaran Hutan Melalui Wireless Sensor Network (WSN) SOFTWARE.

Syadza, Q., Permana, A. G., Ramadan, D. N., \& Pd, S. (2018). PENGONTROLAN DAN MONITORING PROTOTYPE GREENHOUSE MENGGUNAKAN MIKROKONTROLER DAN FIREBASE Controling and Monitoring of Greenhouse Prototype using Microcontroler and Firebase. 4(1), 192-197. 